Ensino, Saúde e Ambiente - V10 (1), pp. 1-26, Abril. 2017

\title{
A EDUCAÇÃO PARA ASTRONOMIA NO ENSINO FUNDAMENTAL: UMA REFLEXÃO ENTRE PROFESSORES E PESQUISADORES
}

\section{THE EDUCATION FOR ASTRONOMY IN ELEMENTARY SCHOOL: A REFLECTION BETWEEN TEACHERS AND RESEARCHERS}

\author{
Alessandra Daniela Buffon ${ }^{1}$, Marcos Cesar Danhoni Neves² \\ ${ }^{1}$ IUniversidade Estadual de Maringá, alessandradbuffon@gmail.com \\ ${ }^{2}$ Universidade Estadual de Maringá, macedane@yahoo.com.br
}

\begin{abstract}
RESUMO
A pesquisa tem como ponto central compreender o grau de importância que os professores atribuem ao Ensino de Astronomia no Ensino Fundamental, assim como, entender os saberes docentes necessários que permitem o enfrentamento dos desafios do cotidiano escolar / acadêmico. Desse modo, estabelecem-se como problemas, inquietudes como: "Qual a importância da Astronomia no Ensino?" e "O que é necessário fazer para ampliar a Astronomia na sala de aula?". Para responder esses questionamentos, os interlocutores da pesquisa são docentes da disciplina de Ciências (Brasil) / Físico-química (Portugal) e pesquisadores da área de formação de professores do Ensino de Astronomia do Brasil e de Portugal. A metodologia utilizada para coleta e análise de dados rege os princípios fenomenológicos. Como resultado, percebe-se que a importância da Astronomia para o ensino é estabelecida por cinco aspectos: os conteúdos relacionados ao tema; a curiosidade; o gosto do aluno; o interesse pela Ciência; e as questões culturais. Para abordar a Astronomia em sala de aula, é necessário dar atenção também para cinco apontamentos: os relatos de experiência; o aperfeiçoamento e a formação docente; os recursos didáticos; a ampliação de tempo; e as atividades experimentais e extracurriculares. A partir dos resultados encontrados, conclui-se que para conquistar um ensino de qualidade, na área de Astronomia, é preciso dar voz aos professores que enfrentam os desafios de introduzir a mesma diariamente nas escolas, a fim de oportunizar formações continuadas voltadas às necessidades emergentes dos docentes.
\end{abstract}

Palavras-chave: Ensino de Astronomia; Formação de Professores; Saberes docentes; Percepção docente; Ensino Fundamental

\begin{abstract}
The research has as its central point to understand the importance that teachers assign to Astronomy Teaching in Elementary School, as well as understanding necessary knowledge for teachers that allow them to face the everyday school and academic challenges. Thus, it is established key questions of concerns and problems like: "What is the importance of Astronomy in school?" And "What is needed to expand the Astronomy in the classroom?". In order to answer these questions the interlocutors of the research are teachers of the discipline of Sciences (Brazil) / Physical chemistry (Portugal) and researchers at the teacher training area of Astronomy Teaching countries of Brazil and Portugal. The methodology used for data collection and analysis are based on phenomenological principles. As a result it can be seen that the importance of Astronomy for teaching is established by five aspects: the content related to the topic; curiosity; the taste of the student; interest in science; and cultural issues. To approach Astronomy in the classroom is necessary to pay attention to five notes: reports of experience; the improvement and the teacher training; teaching resources; the extension
\end{abstract}


of time; and experimental and extracurricular activities. From the results found, it is concluded that in order to achieve a quality education in the field of Astronomy, it is necessary to give voice to teachers who face challenges when introducing it in schools, to provide continuous training aimed at emerging needs of teachers.

Key words: Astronomy teaching; Teacher training; Teachers knowledge; Teacher perception; Primary School.

\section{INTRODUÇÃO}

A Astronomia vem fascinando diversas pessoas por séculos, visto que ela é considerada uma das mais antigas Ciências. Contudo, no Brasil, ela começou a ter mais expressividade nos anos de 1970, quando foi criada a Sociedade Astronômica Brasileira $(\mathrm{SAB})$. Nesse mesmo período surgiram os primeiros estudos voltados à área de ensino, como por exemplo a tese de doutorado de Caniato (1973) que apresentou um minucioso estudo sobre as diferentes razões da importância da Astronomia na escola, ainda pertinentes nos dias atuais.

De acordo com Langhi e Nardi (2009) o Ensino de Astronomia tem crescido consideravelmente nas pesquisas brasileiras nas últimas décadas, apresentando um crescimento de $61 \%$ em dissertações e teses. Ferreira e Voelzke (2012) complementam essa informação através de um estudo onde apontam que durante os anos de 1973 a 2012, o país teve 78 defesas entre teses e dissertações nesta área, evidenciando que a partir do ano de 1996 passou a existir uma expansão e atingiu seu auge em 2006.

Ao estudar sobre o que os professores pensam sobre a Astronomia, pode-se proporcionar melhor entendimento de suas realidades e necessidades, oportunizando melhor compreensão para futuros cursos de formação continuada. Uma vez que, para oferecer um ensino de qualidade aos estudantes é preciso, em primeiro lugar, dar voz aos docentes para tornar a Universidade e a Escola unidas em pró de um único objetivo.

Mediante a tais apontamentos, têm-se como problema as seguintes inquietações: "Qual a importância da Astronomia no Ensino?" e "O que é necessário fazer para ampliar a Astronomia na sala de aula?". A fim de responder tais questionamentos, esse estudo tem como objetivo "compreender o grau de importância que os professores atribuem ao Ensino de Astronomia no Ensino Fundamental e os saberes docentes necessários que permitem o enfrentamento dos desafios do cotidiano escolar / acadêmico para a ampliação da Astronomia em sala de aula”. 
Ensino, Saúde e Ambiente - V10 (1), pp. 1-26, Abril. 2017

\section{EDUCAÇÃO EM ASTRONOMIA NO CONTEXTO BRASILEIRO E PORTUGUÊS}

A preocupação com o Ensino de Astronomia no Brasil surgiu através de pesquisas acadêmicas entre os anos de 1970 e 1980, com um número pequeno de trabalhos, mas com uma extrema significância para a área. Ambos os trabalhos observam uma preocupação com a maneira em que a Astronomia era exposta em sala de aula, levando os pesquisadores a apresentar instrumentos que pudessem proporcionar a ampliação da Astronomia no ambiente escolar.

Os anos de 1990 são marcados fortemente por trabalhos que procuravam identificar as concepções prévias de estudantes e professores sobre o tema Universo, além de analisar os livros didáticos, realizando apontamentos de erros conceituais nesses materiais.

Ao iniciar o século XXI, as pesquisas em Ensino de Astronomia se intensificaram de maneira muito expressiva. Muitos trabalhos ainda continuaram apresentando as concepções prévias ou espontâneas de estudantes e de professores, bem como, a análise de livros didáticos.

Em meados dos anos 2000, é evidenciada uma preocupação com a formação dos professores, uma vez que começam a surgir propostas de cursos de aperfeiçoamento docente e maneiras de inserir a Astronomia nas diferentes modalidades de ensino.

A partir da segunda década dos anos 2000, observa-se que as pesquisas passam a apresentar um novo olhar para o Ensino de Astronomia. Não é mais expressivo um único foco nas investigações. Nesse período, são levadas em consideração as pesquisas anteriores como suporte teórico, uma vez que é possível perceber que as concepções prévias / espontâneas de alunos e professores e os erros mais comuns presentes nos livros didáticos estão mapeados.

\section{A ASTRONOMIA NOS DOCUMENTOS OFICIAIS}

Ao considerar que a Astronomia tem um papel importante para o ensino, os documentos oficiais que regem o Brasil e Portugal apresentam aspectos a esse tema. No Brasil, os Parâmetros Curriculares Nacionais (PCN) surgiram como uma proposta de conteúdos para o Ensino Fundamental, organizados pelo Ministério da Educação em quatro volumes. Tendo em vista que o objetivo deste trabalho é o Ensino de 
Astronomia, serão enfatizados os volumes 01 - Introdução aos PCNs (BRASIL, 1998b) e o volume 04 - Ciências Naturais (BRASIL, 1998a).

De acordo com os PCNs (BRASIL, 1998b), os estudos relacionados ao bloco temático "Terra e o Universo", visam à ampliação da orientação espaço temporal do aluno, a conscientização dos ritmos de vida, e, também, propõem a elaboração de uma concepção do Universo, com enfoque no Sistema Terra Sol-Lua. E em seguida é procurado dar mais ênfase ao Sistema Terra Sol-Lua, uma vez que o aluno já tem construída a concepção de Universo sem fronteiras (BRASIL, 1998a).

Em relação ao sistema de Educação de Portugal, os tópicos de Astronomia foram encontrados nas Orientações Curriculares de Ciências Físicas e Naturais do $3^{\circ}$ ciclo (PORTUGAL, 2001) presente na Disciplina de Físico-química. Ao analisar as Metas Curriculares do $3^{\circ}$ Ciclo do Ensino Básico (PORTUGAL, 2013), observa-se que os assuntos relacionados ao domínio "espaço" estão atribuídos no $7^{\circ}$ ano, tendo como subdomínios: Universo; Sistema Solar; Distância no Universo; Terra, Lua e forças gravitacionais.

\section{FORMAÇÃO DE PROFESSORES PARA A EDUCAÇÃO EM ASTRONOMIA}

Ao pensar sobre lecionar conteúdos relacionados à Astronomia, constate-se que a situação é grave. De acordo com Macêdo (2014), o curso de Licenciatura em Ciências Biológicas tem como um dos objetivos de formar profissionais para atuarem nos anos finais do Ensino Fundamental, no entanto, os acadêmicos não são preparados para ensinar tópicos básicos de Astronomia.

Ao analisar as Diretrizes Curriculares Nacionais para os Cursos de Ciências Biológicas (BRASIL, 2001), é possível constatar que a Astronomia não aparece de maneira clara dentro dos conteúdos básicos estabelecidos por lei. O documento apenas ressalva que é necessário abordar os fundamentos das Ciências Exatas e da Terra, que são entendidos como: conhecimentos matemáticos, físicos, químicos, estatísticos, geológicos e outros fundamentais para o entendimento dos processos e padrões biológicos. Mediante esse documento, pode-se interpretar que a Astronomia é citada indiretamente nos fundamentos físicos, mas isso cabe a cada Instituição de Ensino Superior entender dessa maneira.

Bretones (1999) apresenta uma vasta pesquisa que teve por objetivo identificar as instituições de Ensino Superior que apresentavam conteúdos de Astronomia nas 
disciplinas de formação inicial em Astronomia, Física, Ciências, Geografia e Geofísica, concluindo que uma pequena quantidade contempla a abrangência desse tema. A análise vai ao encontro de Carvalho e Gil-Pérez (1993) ao ressalvarem que os professores de Ciências, além de carecer de uma formação adequada, também não têm consciência de suas insuficiências.

Em Portugal, para lecionar no Ensino Básico, nas disciplinas específicas, o professor precisa ser formado em uma licenciatura base $\left(1^{\circ}\right.$ ciclo $)$ e ter o mestrado em Ensino ( $2^{\circ}$ ciclo). Uma vez que, conforme o documento "Políticas de formação de professores em Portugal" do Ministério da Educação, "No contexto do Processo de Bolonha, a qualificação profissional que habilita para a docência será adquirida, a partir de 2007/2008, apenas através da frequência de cursos do $2^{\circ}$ Ciclo do ensino superior que conferem o grau de mestre" (PORTUGAL, 2007, p.7).

Nesse prisma, para ministrar a disciplina de Físico-química do $3^{\circ}$ ciclo do Ensino Básico, desde 2007, o professor deve ter Licenciatura em Física ou Química e mestrado em Ensino de Física e Química. Visto que, de acordo com o Decreto 43/2007 (PORTUGAL, 2007), o docente com essa formação está habilitado a lecionar para o $3^{\circ}$ Ciclo do Ensino Básico. Contudo, conforme a SPA (2015), tópicos de Astronomia não fazem parte de muitas das licenciaturas-base de formação, acarretando dificuldades para os que vão lecionar em sala de aula.

\section{FORMAÇÃO DE PROFESSORES: TRAJETÓRIAS FORMATIVAS DOCENTES, SABERES E IDENTIDADE DOCENTE.}

As trajetórias formativas docentes são consideradas importantes e significativas na vida dos professores, de modo que Langhi e Nardi (2012) as definem como: trajetória formativa docente inicial, trajetória formativa docente intermediária, trajetória formativa docente na carreira e a trajetória formativa docente pós-carreira. Elas são compostas por distintas fases que podem ou não, acontecer simultaneamente. Como referencial teórico destaca-se Huberman (1995), Tardif (2007), Silva (2005).

Ao pensar sobre as trajetórias formativas docentes, associa-se aos saberes docentes, uma vez que são eles responsáveis pela postura e mudança do professor em sala de aula. Langhi e Nardi (2012) apresentam um vasto estudo sobre as diferentes tipologias dos saberes docentes, segundo os autores da área, procurando efetuar possíveis aproximações entre eles. Os principais saberes docentes identificados na 
literatura e adaptados por eles foram: saberes dos conteúdos a serem ensinados; saberes dos conteúdos pedagógicos, saberes didáticos dos conteúdos a serem ensinados; saberes curriculares, saberes dos contextos; saberes culturais; saberes sobre os alunos; saberes pessoais; saberes pré-profissionais; saberes experienciais da profissão docente; saberes profissionais gerais; e saberes competenciais.

Nessa perspectiva, Gauthier et al (2013), Pimenta (1999) e Tardif (2007) acreditam fortemente que o professor é constituído de saberes, envolvendo toda a trajetória de vida. Langhi e Nardi (2012) acrescentam que, para o desenvolvimento desse aglomerado de saberes, é preciso ter competências e habilidades em cada um deles.

Entende-se que a identidade profissional docente emerge de um contexto histórico pelas reflexões que o docente faz e compartilha com um grande grupo e pela autonomia profissional. Ela é individual e está em constante mudança devido à reconstrução dos saberes docentes.

Portanto, os estudos relacionados sobre os saberes docentes são de grande importância para o ensino, uma vez que são eles responsáveis em desenvolver a autonomia do professor e consequentemente, construírem a identidade docente do mesmo. Tais compreensões podem auxiliar o docente para um autoconhecimento e mostram que a reflexão sobre a experiência é um dos fatores decisivos para um ensino de qualidade.

\section{ENCAMINHAMENTOS METODOLÓGICOS}

A pesquisa é caracterizada de natureza qualitativa, embasada em uma perspectiva fenomenológica, fazendo o uso de um conjunto de asserções com o objetivo de descobrir "fatos" e "causas". Portanto, estudos fenomenológicos procuram entender a significação de acontecimentos e interações humanas em situações particulares (BOGDAN; BIKLEN, 1994).

A Fenomenologia (Phenomenon + Logos) é denotada como o discurso sobre "aquilo como é". Ela busca realidades, não como individualidades singulares, mas na "essência” (HUSSERL, 2006). Ou seja, procura entender os discursos sobre o que e como se mostra em todos os aspectos: históricos, sociais, políticos, sentimentais e da vivência do homem. 


\section{Interlocutores}

- Quatro docentes dos anos finais do Ensino Fundamental na disciplina de Ciências (Brasil) e de Físico-química (Portugal) formados em áreas diversas, com desejo e engajamento pela proposta de contribuir com a investigação;

- Quatro pesquisadores com trabalhos desenvolvidos na área de Formação de Professores para o Ensino de Astronomia no Brasil e em Portugal, com desejo e engajamento pela proposta de contribuir com a investigação.

\section{As estratégias e instrumentos de coletas dos dados}

A partir dos sujeitos de pesquisa definidos, deu-se a continuidade ao estudo sob os pressupostos da pesquisa de natureza qualitativa, sendo que os instrumentos e procedimentos para a coleta de dados foram narrativas/discursos gravados em vídeo.

Conforme o método fenomenológico, os discursos foram iniciados com interrogação direta do fenômeno, uma vez que Neves (2005) salienta que é dever do pesquisador fazer uma formulação de interrogação significativa, articulando os resultados com o tema tratado.

\section{As estratégias e instrumentos de análise dos dados}

Martins e Bicudo (1989) ressaltam que, embora a descrição seja o instrumento de acesso à "vida" do sujeito, a análise dessas descrições ainda não implica necessariamente a uma teoria cientificamente orientada. Isso significa que existem diferentes maneiras de chegar-se à essência do fenômeno.

Ao transcrever as narrativas, assim como todo o contexto que as cercam, foram obtidas as descrições. A partir das leituras das mesmas, iniciou-se a fase principal da Fenomenologia: a redução fenomenológica. De acordo com Husserl (2006), essa redução leva o fenômeno psicológico a sua essência, onde nada é explicado sobre o fenômeno, apenas o descreve.

Por meio de cada discurso lido e relido diversas vezes, trechos de discurso ingênuo são excluídos, ou seja, trechos "que comportam aparentes inessencialidades" (NEVES, 2005, p. 51). Os fragmentos que permaneceram podem revelar as essências do fenômeno posto em questão. Surgem assim, as primeiras "unidades de significados. 
Ressalta-se que essa etapa é de caráter pessoal de cada pesquisador, o que é significativo para um pode não ser para o outro.

Ao definir as Unidades de Significado, passa-se à fase da compreensão da situação relatada da unidade, "caracterizada por uma transformação das expressões usadas pelos sujeitos em uma linguagem pisicológica" (NEVES, 2005, p. 52).

O passo seguinte foi a realização da "compreensão ideográfica" de cada sujeito. Trata-se, como já foi dito, de uma análise da ideologia que permeia as descrições do sujeito (MARTINS; BICUDO, 1989).

A partir da finalização das representações ideográficas, procurou-se ir para a análise psicológica do geral, ou seja, chegar às categorias, convergindo, assim, os discursos entre os sujeitos. Definidas as categorias, foi realizada a compreensão eidética das mesmas.

Por fim, a partir das compreensões individuais dos sujeitos e da compreensão geral, foi finalizada a redução fenomenológica, sendo possível chegar à essência do fenômeno, buscando compreender a importância da Astronomia no ensino e o que necessário fazer para ampliar ela em sala de aula.

\section{ANÁLISE E DISCUSSÃO DOS RESULTADOS}

A análise e discussão dos resultados é compreendida pela redução fenomenológica, em que a primeira etapa a ser realizada, a partir de leituras sucessivas, é identificar as Unidades de Significado, ou seja, trechos que expressem respostas para as interrogações realizadas durante as entrevistas. É necessário, durante esse processo, centralizar no objetivo da pesquisa e nas interrogações que conduzem para a essência do fenômeno - "Qual a importância da Astronomia no Ensino?” e “O que é necessário fazer para ampliar a Astronomia na sala de aula?’.

Com as unidades de significado definidas, busca-se realizar a "compreensão da situação relada da unidade”. A partir de tais análises, é possível realizar a compreensão ideográfica de cada sujeito em sua essência. Com a intenção de exemplificar esse processo, o quadro 01 apresenta a análise individual do sujeito 5. A coluna do lado esquerdo representa asunidades de significadoe a do lado direito assuas respectivas compreensões da situação relatada do sujeito. No final da tabela há uma síntese da compressão ideográfica do sujeito. 
Quadro 01: análise individual do sujeito 5

\begin{tabular}{|c|c|c|}
\hline & Unidade de Significado $^{1}$ & Compreensão da situação relatada \\
\hline 1 & $\begin{array}{l}\text { "[...] é a possibilidade de atrair o aluno } \\
\text { para uma área de interesse no campo da } \\
\text { ciência que daí não se restringe só a } \\
\text { Astronomia, mas ela faz interface com } \\
\text { Geografia, com Física, com Matemática, } \\
\text { com Biologia, com Química..." } \\
\text { "Acho que é uma forma de atrair" } \\
\text { "Eu vejo a Astronomia desta forma na } \\
\text { Educação Básica, como uma possibilidade } \\
\text { de atrair o aluno para essa área científica } \\
\text { que é uma área desinteressante aos olhos } \\
\text { da grande parte da sociedade, hoje em dia" } \\
\text { "Então eu acho que a Astronomia tem essa } \\
\text { importância de atrair o pessoal para essas } \\
\text { outras áreas, acho que é isso" }\end{array}$ & $\begin{array}{l}\text { A Astronomia se torna importante para a } \\
\text { compreensão do espaço em que o ser humano ocupa, } \\
\text { assim como, para entender o seu lugar dentro do } \\
\text { universo. De acordo com o sujeito, saber aspectos } \\
\text { astronômicos leva a entender a cultura que cerca a } \\
\text { humanidade, desde crenças e verdades }\end{array}$ \\
\hline $1 *$ & $\begin{array}{l}\text { "[...] eu acho que uma forma de tentar } \\
\text { trazer a Astronomia é oferecer isso, é } \\
\text { oferecer uma formação que contemple a } \\
\text { Astronomia" } \\
\text { "[...] eu acho que uma forma de trazer a } \\
\text { Astronomia ali ou incentivar, seria } \\
\text { começar pensando na formação inicial do } \\
\text { tal que está se formando na universidade e } \\
\text { continuada para aqueles que já estão lá, } \\
\text { supriria" }\end{array}$ & $\begin{array}{l}\text { Ao ser indagado sobre o que é necessário fazer para } \\
\text { ampliar a Astronomia em sala de aula, o sujeito } \\
\text { apresenta uma das carências que envolvem esse } \\
\text { assunto, referindo-se ao preparo docente para } \\
\text { abordar o mesmo. Na sua concepção, expressada de } \\
\text { maneira categórica, o primeiro passo é oferecer uma } \\
\text { formação, tanto inicial como continuada em que } \\
\text { contemple tópicos desse tema, afim de melhor } \\
\text { instruir os professores para desenvolverem a mesma } \\
\text { no ambiente escolar. }\end{array}$ \\
\hline $2 *$ & $\begin{array}{l}\text { "[...] tem muita atividade de Astronomia } \\
\text { que é atividade simples, que é possível ser } \\
\text { feita, com materiais extremamente } \\
\text { simples, às vezes até durante o dia" }\end{array}$ & $\begin{array}{l}\text { O sujeito enfatiza que, para se inserir a Astronomia } \\
\text { no contexto escolar, existem diferentes atividades } \\
\text { que podem ser realizadas sem a necessidade do uso } \\
\text { de materiais elaborados e sem a necessidade de } \\
\text { serem realizadas no período do dia. Pode-se entender } \\
\text { que, na concepção do sujeito, há diversos recursos } \\
\text { para se abordar esse tema de maneira acessível, tanto } \\
\text { aos docentes como aos alunos e esses assuntos } \\
\text { representam uma significação relevante para a } \\
\text { aprendizagem. }\end{array}$ \\
\hline \multicolumn{3}{|c|}{ Compreensão Ideográfica do sujeito de pesquisa 5} \\
\hline \multicolumn{3}{|c|}{$\begin{array}{l}\text { Ao deparar-se com as indagações referente à importância da Astronomia no ensino e as maneiras de } \\
\text { ampliá-la é perceptível que o sujeito acredita que, quando o professor aborda o assunto Astronomia no } \\
\text { ensino, ele pode atrair o aluno para a área científica, aguçando o espírito cientista do mesmo. Contudo, é } \\
\text { importante que seja oferecida uma formação inicial e continuada de qualidade para os docentes que } \\
\text { lecionam esse assunto, voltada a aspectos relevantes da Astronomia, bem como, que sejam trabalhadas } \\
\text { atividades de baixo custo para diferenciar as aulas, tornando-as mais interessantes e motivadoras. }\end{array}$} \\
\hline
\end{tabular}

\section{As convergências dos discursos}

A segunda etapa das análises e discussão dos resultados consiste na compressão nomotética. Ela possibilitará a compressão geral da importância da Astronomia e como ampliá-la em sala de aula, sintetizando as percepções dos sujeitos envolvidos por meio das convergências dos oito discursos.

\footnotetext{
${ }^{1}$ Para a interrogação "Qual a importância da Astronomia no Ensino?” é atribuída, para as Unidades de Significado, a numeração 1, 2, 3, 4, etc. Já, para o outro questionamento "O que é necessário fazer para ampliar a Astronomia na sala de aula?", a numeração das Unidades de Significado é expressa por 1*, 2*, $3^{*}, 4^{*}$, etc.
} 


\section{Ensino, Saúde e Ambiente - V10 (1), pp. 1-26, Abril. 2017}

Após a releitura de todas as unidades de significado, analisam-se as diversas convergências nascidas, tanto em cada um dos discursos, como entre os discursos. Desse modo, essas convergências são apresentadas como "categorias convergenciais" oriundas das essências captadas.

O Quadro 02 apresenta as dez categorias encontradas. A segunda coluna, intitulada "Convergências", é subdividida em oito subcolunas que identificam as convergências para os oito discursos. As abreviações que aparecem nessas subcolunas (a letra $U$ seguida de um número) representam as unidades em que estão as convergências.

Após o Quadro 02, as categorias serão apresentadas em sua nova essência construída por meio da convergências das unidade de significado dos sujeitos de pesquisa, ou seja, elas sofrem um novo processo de compreensão (a redução novamente em processo) das essências obtidas e que são sintetizadas em uma Compreensão Eidética das Convergências na Categoria.

Quadro 02: As convergências dos discursos, agrupados segundo as categorias encontradas.

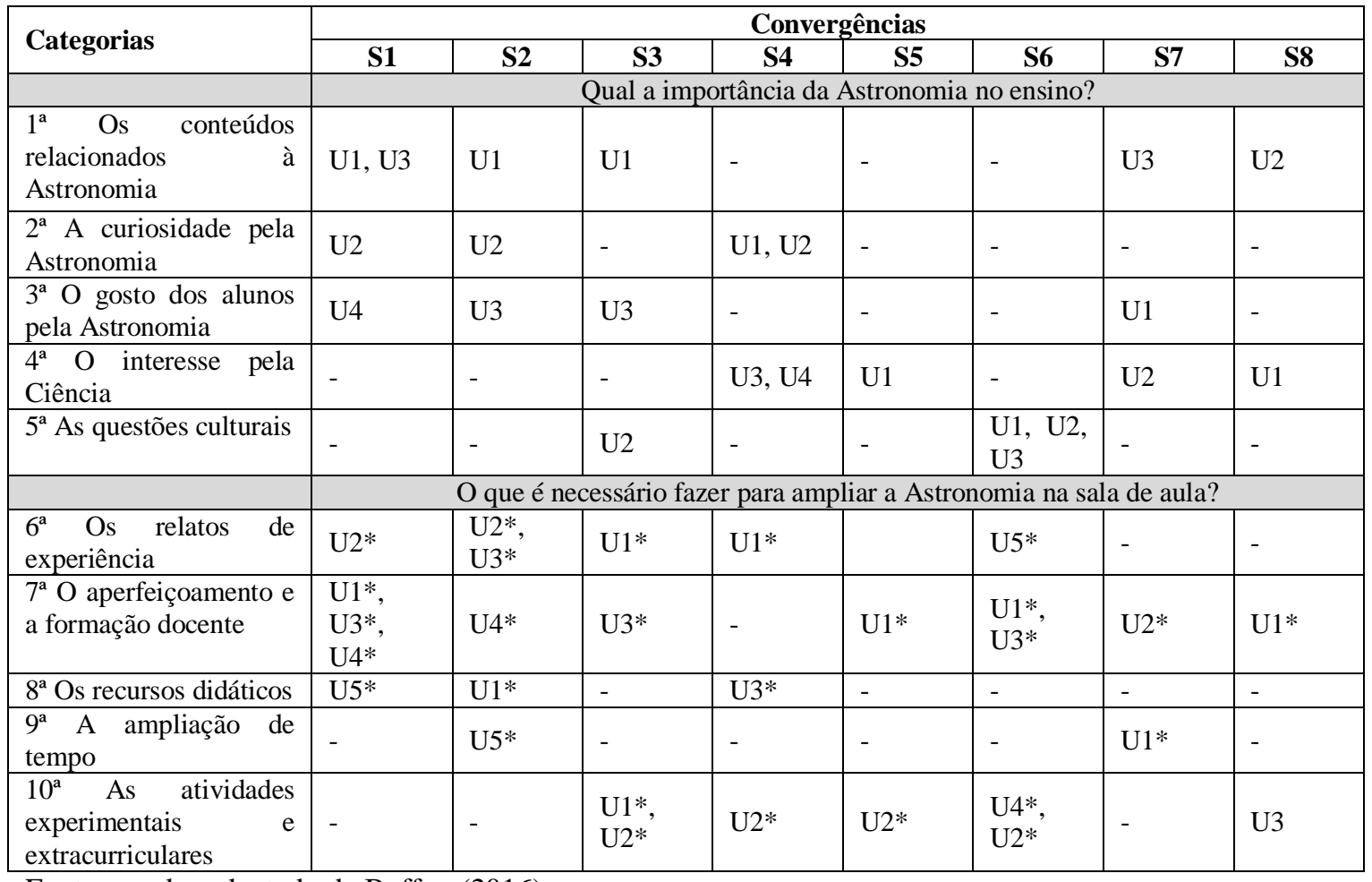

Fonte: quadro adaptado de Buffon (2016) 
Ensino, Saúde e Ambiente - V10 (1), pp. 1-26, Abril. 2017

\section{$1^{\text {a }}$ Categoria: Os conteúdos relacionados à Astronomia ${ }^{2}$ - Compreensão eidética das convergências}

Sujeito 1

U1

"Poxa, eu acho que tu pode ter uma noção do todo [...] como a formação do planeta, toda essa questão, o que interfere e até todos os elementos que estão no cosmos eu acho bem interessante, não só a questão da nossa via lacta, mas o todo".

U3 "[...] tentar mostrar para eles essa coisa nobre essa coisa linda que é nosso universo"

Sujeito 2

$\mathrm{U} 1$

"Eu acho que com a Astronomia, eles, como é que vou dizer? [...] entendem melhor o dia e a noite, as estações"

"Eu acho que primeiro entendem direito essa questão do dia e da noite, as estações, como funciona o sistema solar. E os outros assuntos, as características de cada planeta essas coisas, das estrelas"

Sujeito 3

U1

"A Astronomia permite ao aluno conhecer o universo, conhecer aqui, a terra, o local que eles vivem que é mais um bocadinho que o universo"

“[...] é assim para um ser humano perceber a sua situação no universo primeiro precisa perceber alguma coisa de Astronomia, portanto acho que em termo de cultura geral é bastante importante sabermos onde vivemos?, onde estamos?, o que fazemos aqui? E todas essas questões são respondidas pela Astronomia"

Sujeito 7

U3

"[...] acho que dá uma perspectiva interessante do nosso lugar no universo"

Sujeito 8

$\mathrm{U} 2$

"[...] contribuição para poder usar a Astronomia como forma de motivar para estudarem aquela parte da composição dos elementos"

A Astronomia é considerada importante em ser ensinada quando se pensa sobre os conteúdos abordados dentro desse assunto. Através dela, o aluno passa a ter uma percepção do universo que o cerca, uma vez que são trabalhados tanto assuntos básicos, como as estações do ano e o sistema solar, quanto assuntos complexos, como a origem do universo.

Em relação aos assuntos básicos, os discursos convergem mostrando que é imprescindível ensinar ao aluno, questões como: as características do dia e da noite, solstício de inverno e de verão e os elementos presentes na via láctea. Ao pensar na origem do universo, procura-se, através da Astronomia, estimular a aprendizagem e os

\footnotetext{
${ }^{2}$ Esta categoria apresenta as Unidades de significado dos sujeitos atribuídas a ela, a fim de uma melhor compreensão das etapas da redução fenomenológica.
} 
questionamentos sobre a sua existência enquanto ser humano. Barrio (2014) também acredita na importância em transcorrer esses conteúdos, visto que são questões cotidianas que determinam a vida no dia a dia das pessoas.

Ver os conteúdos da Astronomia como algo fundamental, pode ser atribuído por ela ser uma das mais antigas e belas Ciências desenvolvidas pela civilização humana (PEREIRA; FUSINATO, 2007; PEREIRA; NEVES, 2011). Por meio dela, os estudantes podem se auto compreenderem devido à localização de mundo que ela proporciona.

Nota-se que os aspectos relacionados aos conteúdos abordados dentro da Astronomia, são apontados pela maioria dos sujeitos entrevistados, mostrando que esse aspecto é algo relevante para professores e para pesquisadores. De acordo com Camino e Terminiello (2014, p.423),

\footnotetext{
[...] ensinamos Astronomia porque consideramos que essa disciplina e a Educação por meio dela são formas de nos comunicar com as pessoas com base na experiência em comum do contato com o céu. Além disso, é uma maneira de contribuir, como educadores, para que outros incorporem novos elementos a suas a visões de mundo.
}

Portanto, ao trabalhar os tópicos relacionados à Astronomia, no ambiente escolar, faz com que a noção de mundo dos estudantes seja ampliada, mostrando a eles a imensidão do Universo.

\section{$2^{\text {a }}$ Categoria: A curiosidade pela Astronomia- compreensão eidética das convergências}

A curiosidade que os alunos têm pela Astronomia aparece de maneira marcante ao pensar nos aspectos de importância em abordá-la no ensino de Ciências. Isso vai ao encontro com as ideias de Langhi e Nardi (2012, p. 109) ao afirmarem que Astronomia "[...] revela um universo que promove curiosidade, admiração, imaginação, desenvolvendo o senso de exploração e descoberta". Esse senso de exploração e descoberta pode ser também atribuído devido aos alunos estarem em uma fase de mudança por conta da passagem da pré-adolescência para a adolescência.

Destaca-se que pensar na importância da Astronomia para despertar a curiosidade dos alunos é um fator evidenciado apenas pelos professores da Educação Básica, uma vez que, nos discursos dos pesquisadores, tal aspecto não é enfatizado. 


\section{$3^{\text {a }}$ Categoria: O gosto dos alunos pela Astronomia - compreensão eidética das convergências}

Um dos fatores de grande relevância evidenciado nos discursos dos sujeitos é a respeito do gosto dos alunos por assuntos relacionados à Astronomia. Muitos dos entrevistados acreditam que é necessário levar em consideração o que os estudantes gostam para, então, planejar uma aula que vá ao encontro com as suas expectativas.

Nessa perspectiva, entende-se que "É raro encontrarmos uma pessoa que não se encante com algum conteúdo astronômico" (SANZOVO; QUEIROZ; TREVISAN, 2014, p. 106), levando-os a quererem saber cada vez mais, uma vez que eles têm afinidade com os assuntos, devido a gostarem muito do mesmo.

\section{$4^{\mathrm{a}}$ Categoria: $O$ interesse pela Ciência - compreensão eidética das convergências}

A Astronomia tem a possibilidade de fazer interface com outras disciplinas do ramo científico, atraindo os alunos para a Ciência, ao instigar neles esse interesse. De acordo com Pereira e Fusinato (2007, p. 174), “A Astronomia pode ser considerada um "motor" poderoso o suficiente para despertar a curiosidade pela ciência", uma vez que, ela, seguindo esses mesmos autores, pode ser considerada "uma disciplina especialmente apropriada para motivar alunos e professores, aprofundando o conhecimento em diversas áreas do saber: Física, Química, Matemática, Biologia, Computação, Geografia, História e Antropologia" (PEREIRA; FUSINATO, 2007, p. 174).

A importância da Astronomia, associada ao interesse do estudante pela Ciência, aparece de maneira ampla nos discursos dos pesquisadores e em apenas um discurso de professor da Educação Básica. Nota-se que existe uma maneira diferente de pensar, entre os dois grupos de sujeitos, referente ao mesmo assunto.

No discurso do professor, observa-se que o mesmo descreve como o aluno recebe a Astronomia e o que isso resulta para a vida dele. Já os pesquisadores, enfatizam o grau de importância da Astronomia para atrair o aluno, principalmente ao ressaltar que ela é interdisciplinar sem evidenciar como o aluno a recebe.

Langhi e Nardi (2012, p. 108) destacam que "O papel da Astronomia inclui promover no público o interesse, a apreciação e a aproximação pela ciência geral". Portanto, os discursos se tornam significantes quando procuram entender a 
funcionalidade em estudar Astronomia, uma vez que ela carrega a interdisciplinaridade e a probabilidade de atrair o aluno para a área científica, bem como desenvolver nele um senso crítico.

\section{Categoria: As questões culturais - compreensão eidética das convergências}

A Astronomia é importante em ser ensinada ao perceber que, através dela, o ser humano pode entender sua história, já que ela envolve o estudo de questões culturais. Conforme Barrio (2014, p. 35), a Astronomia "promove o desenvolvimento social, tecnológico, científico por meio da formação de uma cultura geral dos cidadãos”. No entanto, esse aspecto não é expressivo para todos os interlocutores, visto que, em apenas dois discursos, esse fator é evidenciado, sendo uma mistura de professor e pesquisador.

Apesar do pequeno número de sujeitos terem atribuído a importância da Astronomia para estudar aspectos culturais, esses discursos são incisivos e significantes ao pensar nessa perspectiva. Os interlocutores pontuam em diferentes momentos que a Astronomia é imprescindível para questões que envolvem a existência do Universo.

Ao pensar em questões culturais, por meio da Astronomia, é possível, também, desmistificar mitos, bem como, conhecer o conjunto de cientistas que contribuíram ao longo da história para os estudos do Cosmos. Nessa perspectiva, de acordo com Kantor ( 2014, p. 28),

A diversidade de interpretações do céu e os incontáveis mitos que o têm como palco permitem explorar os múltiplos olhares que foram lançados sobre o Cosmo, a pluralidade de ideias, e compreender como se estabeleceram as diferentes visões de mundo de cada cultura.

Portanto, pode-se olhar o estudo da Astronomia como uma questão vital em que qualquer ser humano devesse conhecer o mínimo do Universo que o cerca para entender os mitos, aspectos religiosos e científicos que envolvem a Astronomia. Consequentemente, mostrar ao aluno que ao longo da história diferentes verdades foram aceitas, evidenciando que não existe uma única certeza.

\section{$6^{\text {a }}$ Categoria: Os relatos de experiência - compreensão eidética das convergências}

Ao serem questionadas sobre o que é necessário fazer para ampliar a Astronomia em sala de aula, de maneira unânime, os sujeitos, que representam o grupo 
de professores da Educação Básica, responderam por meio dos relatos de suas próprias experiências em sala de aula. Isso pode ser compreendido por meio das palavras de Tardif (2007, p. 56) ao afirmar que a identidade docente "[...] carrega as marcas de sua própria atividade, e uma boa parte de sua experiência é caracterizada por sua atuação profissional".

As experiências, com o Ensino de Astronomia, evidenciadas, utilizam diferentes meios de comunicação como: documentários, noticiários, revistas e jornais. Fica claro que a mídia influencia diretamente para diversificar as aulas. Apenas um sujeito ressalta atividades práticas que envolvam materiais para construírem juntamente com os alunos.

Observa-se que o fator experiência é algo significativo para os professores, pois eles se sentem confortáveis em relatar como e com o que trabalham em sala de aula. Para Pimenta (1999), os saberes experienciais são produzidos na vivência do professor em sala de aula, num processo contínuo de reflexão sobre a prática.

No entanto, nota-se que o mesmo não acontece com os pesquisadores. Na sua grande maioria, não destacam o que fazem para ampliar a Astronomia em sala de aula. Portanto, isso mostra a importância em dar voz àqueles que trabalham dia-a-dia e enfrentam os desafios em ministrar um conteúdo com tal teor de complexidade.

\section{$7^{\text {a }}$ Categoria: $O$ aperfeiçoamento e a formação docente - compreensão eidética das convergências}

O aperfeiçoamento e a formação docente são percebidos como algo de relevância para ampliar a Astronomia em sala de aula, tanto na visão dos professores da Educação Básica, como dos pesquisadores da área. Ao longo dos discursos, são feitos apontamentos quanto à formação inicial, formação continuada e preparação para lecionar a disciplina.

Tais apontamentos estão de acordo com Brisch, Barros e Silva (2014, p. 198), de modo que eles acrescentam que "a implementação efetiva, com qualidade, do Ensino de Astronomia na Educação Básica, todavia, ainda enfrenta sérios desafios, dentre eles, um dos mais importantes, senão o principal é a fraca, ou a inexistente formação da Educação Básica em Astronomia”.

Em relação à formação inicial, nota-se que os discursos convergem para a declaração de uma falha nesse processo. Em diferentes momentos, eles afirmam que em 
sua formação não há tópicos de Astronomia, mesmo que isso seja obrigatório para a Educação Básica. Nessa perspectiva, muitos dos sujeitos acreditam que é necessário existir uma obrigatoriedade na ementa curricular do Curso Superior de uma disciplina referente aos aspectos astronômicos lecionados. Sanzovo, Queiroz e Trevisan (2014, p. 106) salientam que “[...] apesar dessa ligação natural entre o homem e o céu, é difícil encontrarmos professores de Ciências que contaram com conteúdos de Astronomia em sua formação (inicial ou continuada)".

Devido à inexistência dessa obrigatoriedade, muitos docentes se sentem inseguros e despreparados para lecionar o respectivo conteúdo. Com isso, é preciso que existam cursos de formação continuada para suprir as carências deixadas pela formação inicial, bem como motivar os professores em cursá-los, visto que os saberes disciplinares são oriundos da formação inicial e/ou continuada por meio do contato com disciplinas oferecidas nas universidades para os diferentes campos do conhecimento (TARDIF, 2007).

$\mathrm{Na}$ percepção dos sujeitos, é importante oferecer essa formação para que o conteúdo ganhe significância dentro da matriz curricular da Educação Básica, bem como, permita aos professores conhecerem pesquisas sobre as concepções espontâneas que podem ter seus alunos, uma vez que o conhecimento do saber das Ciências da Educação pode mediar a maneira do docente como profissional (GAUTHIER et al, 2013).

Nessa perspectiva, Carvalho e Gil-Pérez (1993, p. 21) afirmam que a “[...] falta de conhecimentos científicos constitui a principal dificuldade para que os professores afetados se envolvam em atividades inovadoras." Portanto, por meio dos discursos, é perceptível que os docentes da Educação Básica reconhecem suas limitações e quando há a necessidade, procuram aperfeiçoarem-se. No entanto, essa preparação é algo rápido e, muitas vezes, apenas com o uso da internet para auxiliá-los.

\section{$8^{\text {a }}$ Categoria: Os recursos didáticos- compreensão eidética das convergências}

Os recursos didáticos são considerados importantes para ampliar a Astronomia em sala de aula, uma vez que são apresentados pelo grupo de sujeitos que representam os professores da Educação Básica. Observa-se que, mesmo em alguns momentos, eles cogitam que ainda têm poucos recursos didáticos disponíveis nas escolas. Acreditam na relevância em diversificar as aulas com diferenciados instrumentos, principalmente no 
que se refere a recursos audiovisuais. Tais percepções vão ao encontro da ideia de saberes pedagógicos de Pimenta (1999), já que é preciso ensinar, transpondo o conteúdo para uma linguagem escolar com técnicas de didáticas facilitadoras para a aprendizagem.

Contudo, esse apontamento não foi realizado pelo grupo de sujeitos que representam os pesquisadores. Isso pode ser justificado por meio da percepção de Bretones (2014, p. 402), ao afirmar que "Embora seja crescente a produção na pesquisa e os esforços realizados em cursos de formação continuada de professores, muitos recursos são desenvolvidos em projetos episódicos e ainda pouco divulgados em escala nacional".

Portanto, nota-se que existe uma preocupação significativa em tornar a aula diferente e ir além dos livros didáticos, mas ao mesmo tempo, os docentes não sabem ao certo como fazer isso e quais materiais utilizar para difundir a Astronomia no ambiente escolar.

\section{9a Categoria: A ampliação de tempo - compreensão eidética das convergências}

A ampliação de tempo como uma possibilidade de intensificar a Astronomia em sala de aula aparece em apenas dois momentos nos discursos dos sujeitos envolvidos e em perspectivas diferentes. Um deles acredita que é preciso ter mais horas-atividade para planejar a aula, indo de encontro com Langhi e Nardi (2012), que afirmam que a formação limitada em Astronomia dos docentes parece levá-los a algumas situações gerais de despreparo, como o tempo reduzido para pesquisas adicionais a respeito de tópicos astronômicos. Já o outro sujeito destaca que é preciso mais tempo para desenvolver esse assunto no período da aula.

\section{$10^{a}$ Categoria: As atividades experimentais e extracurriculares - compreensão eidética das convergências}

De maneira geral, os sujeitos da pesquisa, tanto pesquisadores como professores da Educação Básica, ressaltam a importância de realizar atividades experimentais para ampliar a Astronomia em sala de aula.

Ao longo dos discursos, é possível observar que os sujeitos se importam com o que a maioria dos estudantes gosta para planejarem suas aulas. Complementam suas 
ideias ao deixar claro que, quando elas são experimentais / práticas, tornam-se altamente atraentes para aqueles que querem aprender. Nessa perspectiva, Neves (2011, p. 13) afirma que "Toda a ciência é compreendida e construída pelo aluno quando ela encerra dentro de si um caráter prático. Mesmo os mais áridos campos do saber nasceram graças a um caráter prático motivador."

Os dois grupos de interlocutores destacam propostas de atividades práticas e extracurriculares. No que se refere à parte experimental, é evidenciada a construção de maquetes para diferentes tópicos dentro da Astronomia. Já para as atividades desenvolvidas fora da sala de aula, são destacadas visitas ao laboratório e observações a céu aberto.

As ideias apresentadas nas entrevistas vão ao encontro de Pereira e Fusinato (2007, p. 183) ao afirmarem que as “[...] atividades práticas de Astronomia para alunos devem oferecer oportunidades para o desenvolvimento de atividades que envolvam trabalhos ao ar livre e que não exigem materiais ou laboratórios custosos". Portanto, é indispensável ensinar a Astronomia de maneira diferenciada e significante aos estudantes, afim de despertar o máximo de interesse possível do aluno.

\section{Compreensão nomotética imediata das situações relatadas pelos oito sujeitos}

Ao longo da redução fenomenológica, objetivando compreender o discurso dos professores, surgem vários pontos de convergência diante das dúvidas essenciais "qual a importância da Astronomia para o Ensino? E o que é necessário fazer para ampliá-la em sala de aula?".

A respeito da importância da Astronomia para o ensino, são evidenciados os seguintes fatores: os conteúdos do assunto, a curiosidade, o gosto, o interesse pela ciência e as questões culturais. Esse conjunto de apontamentos relata a percepção tanto de professores da Educação Básica como de pesquisadores universitários.

O que é ensinado em sala de aula auxilia os alunos a terem uma possibilidade de percepção do universo que os cerca, uma vez que são trabalhados tanto assuntos básicos, como as estações do ano e o sistema solar, quanto assuntos complexos, como a origem do Universo. Ao trabalhar esses assuntos, pode despertar nos alunos certa curiosidade, visto que eles se encontram em uma idade em que o senso do querer saber mais está aguçado. 
Outra percepção importante diz respeito ao gosto que os estudantes demonstram ao abordar Astronomia, uma vez que, dentro do espaço escolar, eles mostram muito interesse pelo assunto por meio de perguntas e dúvidas pertinentes, resultando na possibilidade de atrair o aluno para a Ciência. Ao abordar a Astronomia, é possível trabalhar diferentes disciplinas, visto que ela é considerada interdisciplinar e, consequentemente, desperta neles, interesse por aspectos científicos.

As questões culturais entram em destaque quando se pensa na Astronomia como uma das mais antigas Ciências e proporciona aos alunos discussões que desmistificam mitos envolvendo a cultura a que o ser humano pertence, a religião e o senso comum. Estudar esse assunto faz com que o aluno mude sua concepção de verdade, passando a ter muitas incertezas.

Portanto, os conteúdos abordados na Astronomia são de extrema relevância, uma vez que, por meio deles, é possível despertar nos alunos a curiosidade e o gosto pelo assunto, bem como o interesse pela ciência e discutir questões culturais, motivando-os a quererem saber mais do mundo que os cerca.

Em relação sobre o que é necessário fazer para ampliar a Astronomia em sala de aula, evidenciaram-se cinco aspectos: os relatos de experiência, o aperfeiçoamento e a formação docente, os recursos didáticos, a ampliação de tempo e as atividades experimentais e extracurriculares. Esse conjunto de elementos relata a percepção de professores da Educação Básica e de pesquisadores universitários.

Constatou-se que, quando os professores são questionados sobre o que é preciso fazer, optam por relatar a sua experiência com o assunto. Eles descrevem algumas das atividades que realizam com seus alunos referentes à Astronomia, bem como, enfatizam que é importante existirem momentos de socialização de saberes, afim de proporcionarem novas ideias por meio da vivência com outros docentes da área.

$\mathrm{O}$ aperfeiçoamento e a formação docente apareceram de maneira demasiada entre os discursos, fazendo apontamentos para a formação inicial e continuada e para a preparação do professor antes dele lecionar. A grande maioria dos sujeitos envolvidos acredita na importância da obrigatoriedade de uma disciplina de Astronomia nos cursos em que os professores precisam ensiná-la em sala de aula.

Como ainda existe essa deficiência, é necessário proporcionar a eles uma formação continuada de qualidade e motivá-los a realizá-la, resultando para o aluno, ter uma aula de qualidade. Os discursos também relatam o aperfeiçoamento como algo 
instantâneo e quando surge a necessidade de lecionar assuntos que envolvem a Astronomia.

Outro apontamento analisado como uma possibilidade de ampliar a Astronomia refere-se aos recursos didáticos. Existem muitas pesquisas que abordam e desenvolvem esses materiais, no entanto, muitas vezes, eles não são divulgados em escala ampla que abranja as escolas. Os entrevistados acreditam na importância de trabalhar com recursos diferenciados, como por exemplo, os audiovisuais, com o intuito de atrair a atenção do aluno para o conteúdo. Contudo, para conseguir planejar e executar uma aula diferenciada com qualidade, é necessário que exista a ampliação de tempo, mesmo com um número reduzido de sujeitos que relataram tal aspecto, é importante que seja levado em consideração para o desenvolvimento dos estudantes.

O seguinte aspecto relatado descreve a importância de atividades experimentais e extracurriculares para tornar a aula diferenciada e dinâmica, uma vez que tais atitudes despertam no aluno, muito interesse. Devido à idade em que se encontram, os alunos apresentam uma característica fundamental que vai de encontro com a Astronomia. Realizar trabalhos manuais faz com que o aluno participe intensivamente do processo de construção do seu próprio conhecimento.

Portanto, para ampliar a Astronomia em sala de aula, é preciso proporcionar uma formação inicial para os licenciandos, e uma formação continuada de qualidade para os que estão em exercício, bem como, momentos de troca de experiências entre eles. Os recursos didáticos, as atividades experimentais e extracurriculares, também exercem um papel de relevância para atingir tal objetivo, uma vez que, é por meio deles que os alunos se sentem atraídos pela disciplina. Para que ela se torne significante no ambiente escolar, é preciso, também, ampliar o tempo de preparação dessas aulas, bem como, para desenvolvê-las com os alunos.

\section{Compreensão nomotética geral}

Ao considerar a prática pedagógica como um fenômeno, busca-se "contribuir para que essa prática seja repensada, melhor conhecida e compreendida enquanto realidade complexa, plural e cheia de possibilidades para a mudança da educação" (BUENO, 2003, p. 89). Com isso, as inquietudes iniciais são respondidas em duas perspectivas: na detecção da importância da Astronomia e na compreensão dos saberes 


\section{Ensino, Saúde e Ambiente - V10 (1), pp. 1-26, Abril. 2017}

docentes necessários que possivelmente permitem ampliar o ensino da mesma em sala de aula.

Em relação à relevância da Astronomia para o ensino, observam-se convergências entre as categorias, uma vez que uma é complemento da outra. Os conteúdos destacados são apontados sob duas perspectivas: uma, evidenciando os tópicos para serem desenvolvidos em sala de aula e outra, no que reflete para o aluno essa abordagem. Ao desenvolver a Astronomia no ambiente escolar, permite-se ao aluno ir além do conhecido, proporcionando nele o desejo pela Ciência, além de instigar discussões sobre as questões culturais.

O interesse pela Ciência é visto como uma das razões em estudar Astronomia, devido a sua interdisciplinaridade, podendo despertar no aluno a probabilidade em atraílo para a área científica, bem como desenvolver o seu senso crítico. Em conformidade, as inquietações sobre os mitos, aspectos religiosos e científicos que envolvem essa temática, proporcionam aos envolvidos discutirem e entenderem a existência do Universo por meio das questões culturais, visto que a Astronomia é a mais antiga das Ciências.

Sob outra perspectiva, abordar a Astronomia no ensino pode ser entendido como uma maneira de trabalhar o que os alunos gostam e se identificam, bem como uma forma de usar a curiosidade deles pelo assunto para intensificar o desejo pela Ciência.

Portanto, a importância da Astronomia está diretamente relacionada com os conteúdos que nela são desenvolvidos, visto que eles vão ao encontro do gosto da maioria dos alunos e, consequentemente, despertam a curiosidade e o interesse pela Ciência, bem como, intensificam as discussões referentes aos aspectos culturais.

Ao apreciar que "é fundamental que o homem se perceba como ser-ao-mundo e no-mundo, capaz, conscientemente, de agir nesse mundo e ajudar a criar uma nova realidade" (BUENO, 2003, p. 89), torna-se possível entender os saberes envolvidos nas razões que motivam os professores a ampliarem a Astronomia no ambiente escolar, assim como a compreensão da sua trajetória formativa, uma vez que, conforme a fase em que eles estão vivenciando, tem percepções de mundo diferente.

Os apontamentos apresentados nos discursos podem ser também analisados à luz da fundamentação discutida no capítulo dois sobre a formação de professores, tal como descrita, visto que os sujeitos da Educação Básica encontram-se na 'trajetória formativa de carreira', podendo estar oscilando entre as fases do 'experiente inovador', 
'experiente lamentador' e 'experiente conformado e estratégico'. Isso pode resultar numa atitude, às vezes inovadora, às vezes questionadora, mas de maneira geral, conformada com sua forma de lecionar em sala de aula. Essas etapas costumam permanecer por anos até resultarem no 'afastamento'.

A compreensão das fases formativas dos docentes possibilita um melhor entendimento a respeito das suas atitudes em sala de aula afim de ampliar a Astronomia nesse espaço, uma vez que a postura adotada pelo docente reflete diretamente no momento em que está vivenciando.

Para difundir a Astronomia, podem ser destacados alguns saberes necessários para dar conta da demanda, uma vez que acredita-se na importância dos conhecimentos disciplinares e pedagógicos, bem como na experiência como docente.

Em relação aos conhecimentos disciplinares, destaca-se a relevância de uma formação ampla na área, tanto inicial quanto continuada, uma vez que, para ensinar um determinado conteúdo é preciso antes aprendê-lo nas academias. Essa percepção é uma das categorias mais significativas, visto que os discursos convergem para tal apontamento de maneira quase que absoluta.

Quanto aos conhecimentos pedagógicos, pode ser observado que é preciso ter domínio de tempo para planejar e lecionar em sala de aula, bem como ter uma percepção aguçada dos momentos de realizar atividades extracurriculares, experimentais e de utilização de instrumentos tecnológicos. Pois, é a partir de tal aprendizagem que se desenvolve o docente na área da educação.

Os relatos das vivências no magistério mostram, de maneira categórica, que é extremamente importante escutar os docentes que estão em sala de aula, bem como, valorizar as suas experiências positivas com o assunto. De forma unânime, os discursos dos professores da Educação Básica convergem para a necessidade de uma troca de saberes, visto que cada um carrega o seu.

No tocante dos saberes docentes fundamentais para ampliar a Astronomia em sala de aula, observa-se certa familiaridade com o triângulo do conhecimento de Nóvoa (1999, p. 9), pois, o autor ressalta que

O triângulo do conhecimento procura traduzir a existência de três grandes tipos de saberes: o saber da experiência (professores); o saber da pedagogia (especialistas em Ciências da educação); e o saber das disciplinas (especialistas dos diferentes domínios do conhecimento) (NÓVOA, 1999, p. 9) 
Em conformidade, as categorias $6^{\mathrm{a}}, 7^{\mathrm{a}}$ e $8^{\mathrm{a}}$ apresentam elementos que permeiam o saber da experiência, o pedagógico das disciplinas, sendo os mesmos, indispensáveis para ter-se uma educação de qualidade. Esse conjunto de saberes é fundamental para proporcionar a autonomia do professor e, consequentemente, a sua identidade docente. A evolução das trajetórias formativas e dos saberes a serem desenvolvidos resulta, diretamente na mudança de postura em sala de aula.

Por fim, entende-se que a Astronomia é importante de ser ensinada no ambiente escolar e para conseguir ampliá-la em sala de aula, é necessário desenvolver os saberes disciplinares e curriculares, bem como, valorizar os experienciais. Uma vez que ela tem um grande potencial de atrair o aluno para a Ciência e se o professor for mais bem compreendido, será possível sanar as suas dificuldades e isso resultará diretamente em um ensino de melhor qualidade a todos os envolvidos na área da Educação.

\section{CONSIDERAÇÕES FINAIS}

Ao realizar as narrativas fenomenológicas com os professores interlocutores dessa pesquisa, procurou-se deixá-los expressarem-se livremente, a fim de entender a sua relação com a Astronomia e com o contexto escolar que esses sujeitos estavam inseridos. Percebeu-se que o fato de eles falarem livremente, causou-lhes certa insegurança no início e, em muitos momentos, ficavam sem o que dizer, contudo, ao longo do discurso foi perceptível o engajamento e a ânsia de colaborar com a pesquisa.

Para conquistar um ensino de qualidade, na área de Astronomia, é preciso dar voz aos professores que enfrentam os desafios de introduzir a mesma diariamente nas escolas, contrapondo seus discursos com os pesquisadores dessa área, estreitando a relação entre universidades e escolas, a fim de oportunizar formações continuadas voltadas às necessidades emergentes dos docentes.

Como perspectivas para futuras pesquisas, ficam sugestões de cursos de formação continuada voltados a entenderas experiências positivas que os professores têm em suas aulas, oportunizando momentos de reflexão e de troca de saberes. Uma vez que, por meio desse espaço, podem surgir propostas inovadoras para diferentes realidades que o professor está habituado a trabalhar.

\section{Agradecimentos}

Agradeço a CAPES pela concessão da bolsa de estudos. 
Ensino, Saúde e Ambiente - V10 (1), pp. 1-26, Abril. 2017

\section{REFERÊNCIAS}

BARRIO, Juan Bernadino Marques. Conteúdos Conceituais, procedimentais e Atitudinais no Ensino da Astronomia. In LONGHINI, Marcos Daniel (org). Ensino de Astronomia na escola: concepções, ideias e práticas. Campinas: Átomos, 2014. BOGDAN, Robert; BIKLEN, Sari. Investigação qualitativa em educação. Portugal: Porto Editora, 1994.

BRASIL. Conselho Nacional de Educação. Diretrizes Curriculares Nacionais para os Cursos de Ciências Biológicas. Conselho Nacional de Educação. Brasília: MEC/CNE, 2001.

BRASIL. Secretaria da Educação Fundamental. Parâmetros curriculares nacionais. 2. Ciências Naturais : Ensino de quinta a oitava séries. Brasília: MEC/SEF, 1998a.

BRASIL. Secretaria da Educação Fundamental. Parâmetros curriculares nacionais: terceiro e quarto ciclos do Ensino Fundamental: introdução aos parâmetros curriculares nacionais.Brasília: MEC/SEF, 1998b.

BRETONES, Paulo Sérgio. Atividades didáticas de Astronomia em escolas municipais: palestras, relógios de Sol e Sistema Solar em escala. In LONGHINI, Marcos Daniel (org). Ensino de Astronomia na escola: concepções, ideias e práticas. Campinas: Átomos, 2014.

BRETONES, Paulo Sérgio. Disciplinas Introdutórias de Astronomia nos Cursos Superiores do Brasil. 1999. 200f. Dissertação (Mestrado em GeoCiências).

Universidade Estadual de Campinas, Campinas. 1999.

BRISCH, Sérgio Mascarello; BARROS, Marconi Frank; SILVA, Thiago Pereira. Ensino de Astronomia além da sala de aula: integração de atividades extraclasse ao ensino formal. In LONGHINI, Marcos Daniel (org). Ensino de Astronomia na escola: concepções, ideias e práticas. Campinas: Átomos, 2014.

BUENO, Enilda Rodrigues de Almeida. Prática Pedagógica e fenomenologia. In PEIXOTO, Adão José (org). Interações entre fenomenologia \& educação. Campinas: Alínea, 2003.

BUFFON, A. D.. O ensino de Astronomia no ensino fundamental: percepção e saberes docentes para a formação de professores. 2016.147f. Dissertação (Mestrado em Educação para a Ciência e a Matemática). Universidade Estadual de Maringá, Maringá. 2016.

CAMINO, Néstor; TERMINIELLO, Cristina. Escolas a Céu Aberto: experiência possíveis de Didática da Astronomia. In LONGHINI, Marcos Daniel (org). Ensino de Astronomia na escola: concepções, ideias e práticas. Campinas: Átomos, 2014. CANIATO, Rodolpho. Um projeto brasileiro para o Ensino de Física. 1973. $576 f$. Tese (doutorado em Ciências). Faculdade de educação, Universidade Estadual de Campinas, Campinas. 1973.

CARVALHO, Anna Maria Pessoa de; GIL-PÉREZ, Daniel. Formação de professores de Ciências.São Paulo: Cortez, 1993 (Questões da nossa época) FERREIRA, Orlando Rodrigues; VOELZKE, Marcos Rincon. Análise do bando de dados de teses e dissertações do DME/UFSCar sobre Educação em Astronomia. Anais do Encontro de Produção Discente PUCSP/Cruzeiro do Sul. São Paulo. p. 1-12. 2012.

GAUTHIER, Clermont; MARTINEAU, Stéphane; DESBIENS, Jean-François; MALO, Annie; SIMARD, Denis. Por uma teoria da Pedagogia: Pesquisas contemporâneas sobre o Saber Docente. 3ed. Ijuí: Editora Unijuí, 2013 (coleção fronteiras da educação). 
HUBERMAN, Michaël. O ciclo de vida profissional dos professores. In NÓVOA, António (org). Os professores e as histórias da sua vida. 2ed. Porto: Porto Editora, 1995.

HUSSERL, Edmund. Ideias para uma fenomenologia pura e para uma filosofia fenomenológica. Aparecida: Ideias \& Letras, 2006.

KANTOR, Carlos Aparecido. O céu e a Terra: imagens no espelho. In LONGHINI, Marcos Daniel (org). Ensino de Astronomia na escola: concepções, ideias e práticas. Campinas: Átomos, 2014.

LANGHI, Rodolfo; NARDI, Roberto. Educação em Astronomia: repensando a formação de professores. São Paulo: Escrituras Editora, 2012 (Educação para a Ciência).

LANGHI, Rodolfo; NARDI, Roberto. Ensino de Astronomia no Brasil: educação formal, informal, não formal e divulgação científica. Revista Brasileira de Ensino de Física, v. 31, n. 4, 4402. 2009.

MACÊDO, Josué Antunes de. Formação inicial de professores de Ciências da natureza e Matemática e o Ensino de Astronomia. 2014. 268f. Tese (Doutorado em Ensino de Ciências e Matemática). Universidade Cruzeiro do Sul, São Paulo. 2014. MARTINS, Joel; BICUDO, Maria Aparecida Viggiani. APesquisa Qualitativa em Psicologia: Fundamentos e Recursos Básicos. São Paulo: Morais, 1989.

NEVES, Marcos Cesar Danhoni. O que é isto, a ciência?. Maringá: Eduem, 2005. NÓVOA, Antônio. Profissão Professor. $2^{a}$ Ed. V. 3. Porto Editora: Porto, 1999. (coleção Ciências da educação).

PEREIRA, Ricardo Francisco; FUSIONATO, Polonia Altoé. Desbravando o Sistema Solar: um jogo educativo para o Ensino e a divulgação da Astronomia. In NEVES, Marcos Cesar Danhoni (org). Da Terra, da Lua e além. Maringá: Editora Massoni, 2007.

PEREIRA, Ricardo Francisco; NEVES, Marcos Cesar Danhoni. Adaptando uma câmera fotográfica manual simples para fotografar o céu. In NEVES, Marcos Cesar Danhoni (org). Astronomia e Cosmologia: fatos, conjecturas e refutações. Maringá: Eduem, 2011.

PIMENTA, Selma Garrido. Formação de professores: identidade e saberes da docência. In PIMENTA, Selma Garrido (org). Saberes pedagógicos e atividade docente. São Paulo: Cortez, 1999.

PORTUGAL. Ministério da Educação e Ciência - Direcção Geral dos Recursos Humanos da Educação. Políticas de formação de professores em Portugal. Lisboa: MEC, 2007a.

PORTUGAL. Ministério da Educação e Ciência. Metas curriculares do $3^{\circ}$ ciclo do Ensino Básico: Ciências Físico-químicas. Lisboa: MEC, 2013. PORTUGAL. Ministério da Educação e Ciência. Orientações Curriculares para o $3^{\circ}$ ciclo do Ensino Básico: Ciências Físicas e naturais. Lisboa: MEC, 2001. SANZOVO, Daniel Trevisan; QUEIROZ, Vanessa; TREVISAN, Rute Helena. Estratégias Alternativas para o Ensino de Astronomia. In LONGHINI, Marcos Daniel (org). Ensino de Astronomia na escola: concepções, ideias e práticas. Campinas: Átomos, 2014.

SILVA, Rita de Cassia da. O professor, seus saberes e suas crenças. In GUARNIERI, Maria Regina (org). Aprendendo a Ensinar: o caminho nada suave da docência. 2ed. Campinas: Autores associados, 2005 (coleção polêmicas do nosso tempo).

SOCIEDADE PORTUGUESA DE ASTRONOMIA (SPA). Sobre o Ensino de

Astronomia. Acessado em: 20 de agosto de 2015. Disponível em: <http://www.spAstronomia.pt/ensino_Astronomia>. 
Ensino, Saúde e Ambiente - V10 (1), pp. 1-26, Abril. 2017

TARDIF, Maurice. Saberes Docentes e Formação Profissional. 8. ed. Petrópolis: Vozes, 2007. 